\title{
Passive Microwave Technique for Estimating The Brightness Temperature of Mediterranean Sea Surface
}

\author{
Falih A. Aziz \\ College of Pharmacy \\ University of Mosul
}

(Received 27/11/2012, Accepted 1/9/2013)

\begin{abstract}
The current study is conducted to investigate the insolation parameter in measuring sea surface temperature of Libyan city of Lipda. The process was accomplished at different bands (from 0.7 to $31.4 \mathrm{GHz}$ ), by using a laboratory system for microwave remote sensing in which the insolation parameter was studied with regard to temperature as well as frequencies.

In the present study, the dielectric constant of several water samples from Mediterranean sea were measured at $(0.7$ to $31.4 \mathrm{GHz})$ bands. The amount of reflectivity was hence calculated by Fresnel's law and then the amount of emissivity was found. The "Radiation transfer model" mathematical model was adopted in the current study to calculate the brightness temperature of the seawater as a function of angles with atmospheric effect and non-atmospheric ones. The study has come out with the conclusion that the non-atmospheric effects are less than the atmospheric ones. Sea surface temperature can be used operationally to assess eddies, fronts and upwelling for marine navigation and to track biological productivity.

Keywords: Complex dielectric constant, Emissivity, Radiative Transfer Model Brightness Temperature.

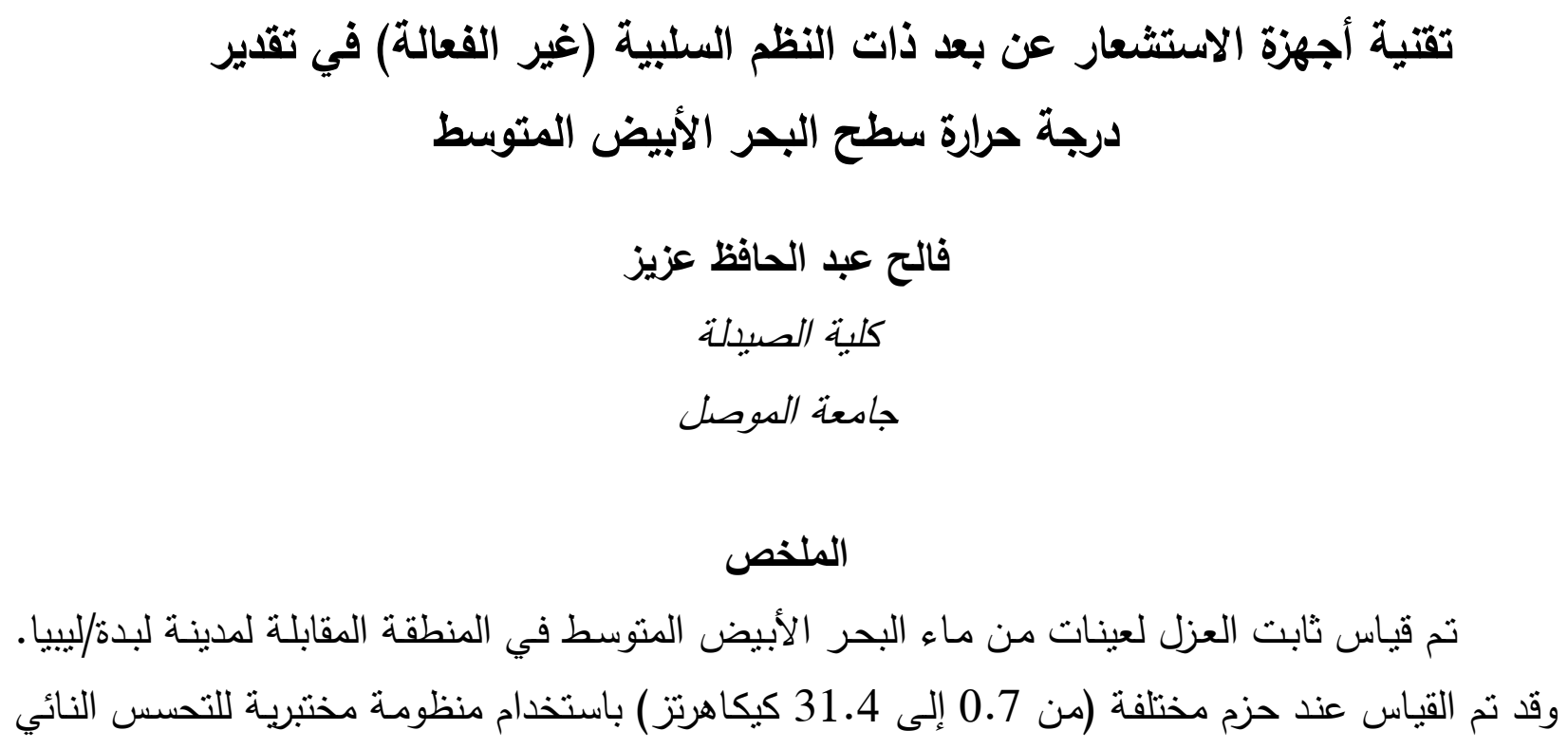


المايكروي، وفيها تم دراسة ثابت العزل وعلاقته مع درجة الحرارة وكذللك علاقته مع التردد. باستخدام قانون (Frensel) في هذه الدراسة طبق الموديل الرياضي (Radiative transfer model) وتم حساب مقداب مندار درجة حرارة السطوع (حرارة الانبعاث الحراري، Brightness temperature) كدالة للزاوية عند وجود

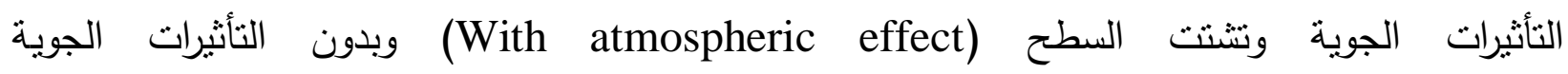
(non-atmospheric effect) وكانت النتائج في الحالة الثانية أقل من تلك التي أخذت فيها التأثنرات

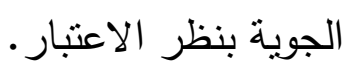
الكلمات الدالة: ثابت العزل، درجة حرارة السطوع، القدرة الانبعاثية للإثشعاع، سطح الماء.

\section{INTRODUCTION}

The ability of remote sensing to identify sea surface temperature has been utilized for many decades. Mapping by passive microwave instruments and earth sea truth, the sea surface temperature from the air or space has allowed the potential to monitor the dynamics of hydrological events through space and time at a consistent level of accuracy (Swift, 1980). The Sea surface (the target) and sensor interaction processin passive microwave remote sensing are governed by the target parameters (dielectric properties, roughness of the sea surface) and the sensor parameters (frequency polarization, incidence angle).

A precise knowledge of the complex dielectric constant $\varepsilon^{*}$ of sea water and fresh water from cloud is essential for studying the radiative transfer of microwave radiation that emitted by the sea surface transmitted through the earth's atmosphere and finally received by passive microwave sensor (Klein, et al., 1977; Lipton, et al., 1999; Thomas and Frank, 2004).

The specular sea surface emissivity $\mathbf{E}_{\mathbf{m}}$ for polarization $\mathbf{P}$ at the earth's incidence angle $\boldsymbol{\Theta}$ (EIA) is determine by the Fresnel equations (Rosen Kranz, 2003; Knight and Llewellyn Jones, 1984). The dielectric constant, which is a function of frequency, water temperature and salinity, enters in two ways into radiateve transfer equations (Rosen Kranz, 2003). In the first case, the $\varepsilon^{*}$ refers to sea water with a surface temperature $\mathbf{T}_{\text {phy }}$. In the second case, the fresh water from cloud is pure and the temperature of cloud is $\mathbf{T}_{\text {sky }}$. Physical retrieval algorithms for environmental data records (EDRS), such as the sea surface temperature (SST), sea surface roughness (SSR), columnar water vapor and columnar liquid cloud water are derived from a radiative transfer model (RTM), which computes the brightness temperatures as a function of these environmental data records. The radiative transfer model is based on a model for the sea surface emissivity and the theory of microwave absorption in the earth's atmosphere (Rosen Kranz, 2003; Meissner, and Wentz, 2003). 
The performance of the environmental data records algorithms depends on the accuracy of sea surface emissivity and therefore on the value of the complex dielectric constant $\varepsilon^{*}$. Moreover, the microwave absorption due to liquid cloud water depends directly on the dielectric constant of pure water through emissivity equation. So far, microwave radiation transfer calculations mainly use the complex dielectric constant.

The brightness temperature of the water surface plays a key role in determining the radiation emitted by the surfacet (Swif, 1980; Wentz, 1983). The emissivity has been calculated by assuming a smooth water surface using Fresnel's relations to calculate reflectivity from dielectric properties of the surface as a function of viewing angle and polarization (Ulaby et al., 1986).

\section{RADIATIVE TRANSFER MODEL FOR SEA}

The emissivity $\left(\mathbf{E}_{\mathbf{m}}\right)$ of a material can be defined as the ratio of brightness temperature of the material to the brightness temperature of a black body at the same temperature ((Wilheit, 1978; Meissner and Wentz, 2004):

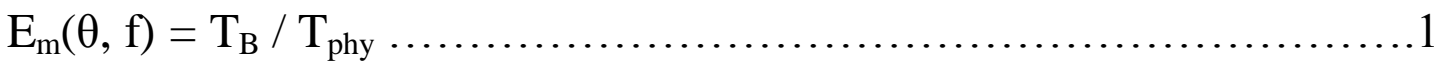

where $T_{B}$ is the brightness temperature of the material, $\boldsymbol{\theta}$ the local incidence angle, $\mathbf{f}$ the frequency, and $\mathbf{T}_{\text {phy }}$ the object's physical temperature.

Note that $\mathbf{T}_{\mathbf{B}}$ is always smaller or equal to the $\mathbf{T}_{\mathbf{p h y}}$ which is that of the black body $\left(E_{m}=1\right)$. Detection of the variations in $\mathbf{T}_{\mathbf{B}}$ of bodies at the same physical temperature enables one to differentiate between types of material, such as fresh and saline water, or land and sea or ocean surfaces. Look angle of a microwave radiometer being an important observational parameter, a study of how brightness temperature depends on it to become particularly important. Considering seawater as the target, the emissivity of seawater varies with salinity, temperature and the surface texture (i.e., roughness and foam coverage). If the height variations of a surface are much smaller than the wavelength of the radiation, such surface is called a smooth or a specular surface. For such smooth surface, the sea can be represented by a flat, infinite, half-space, in this approximation the emissivity is given by(Meissner and Wentz, 2004):

$$
E_{m}(H, V)=1-|R(H, V)|
$$

The reflection from a specular surface boundary is governed by Snell's law and is given by Hidy et al., (1972). 


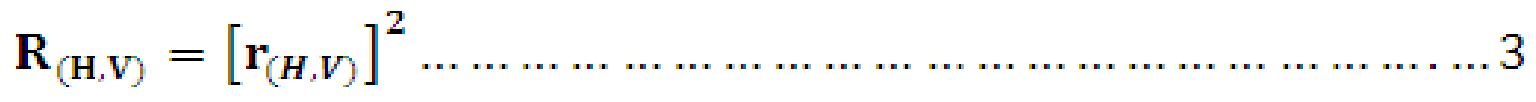

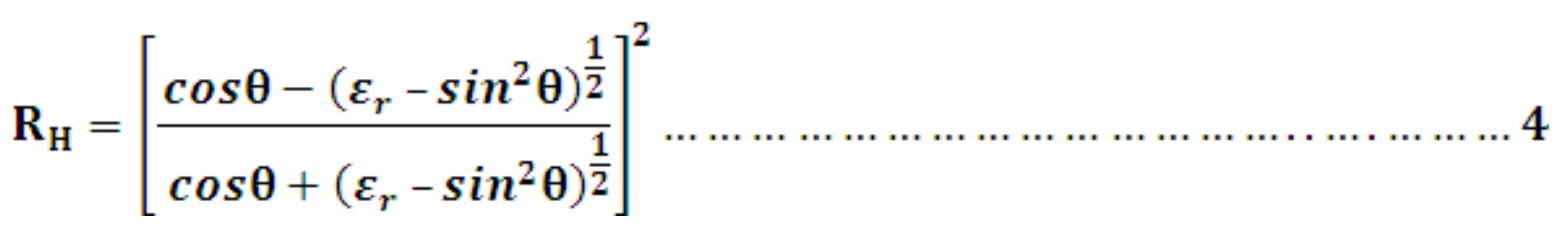

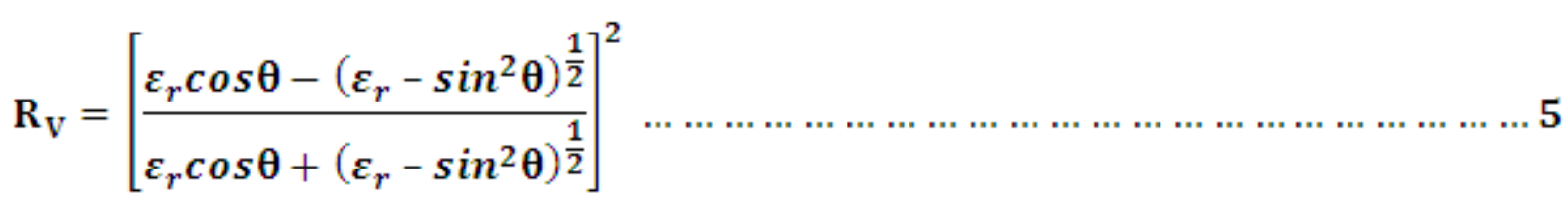

Where $\mathrm{r}$ is power reflection coefficient in both horizontal $(\mathrm{H})$ and vertical (V) polarizations; $\mathrm{R}$ is the reflectivity in both $(\mathrm{H}, \mathrm{V})$ polarization. $\varepsilon_{\mathrm{r}}$ the relative complex dielectric constant $\left(\varepsilon_{\mathrm{r}}=\varepsilon_{1}-\mathrm{j} \varepsilon_{2}\right)$ and $\theta$ is the incidence angle relative to nadir. Radiation received by a radiometer from a given object is composed of a part of emitted thermal radiation and a part of reflected radiation originating from the surrounding. The brightness temperature of the medium as a function of the angle of observation $\theta$ is given as (Wilheit, 1978).

$$
\mathrm{T}_{\mathrm{B}}(\mathrm{H}, \mathrm{V})=\mathrm{E}_{\mathrm{m}}(\mathrm{H}, \mathrm{V}) * \mathrm{~T}_{\text {phy }}+\left[1-\mathrm{E}_{\mathrm{m}}(\mathrm{H}, \mathrm{V})\right] * \mathrm{~T}_{\text {sky }}(\theta)
$$

Look angle of a microwave radiometer is an important observational particularly important:

1- When the atmospheric and surface scattering effects are not taken into account. The relation between brightness temperature of vertically polarized radiation $\left(\mathrm{T}_{\mathrm{BV}}\right)$ and look angle is governed by the relations (Wilheit, 1978):

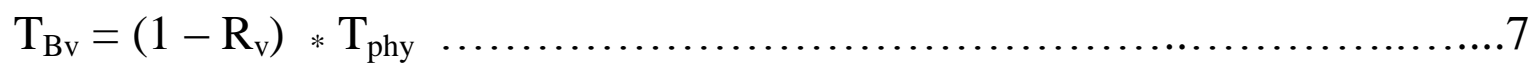

$$
\begin{aligned}
& \mathrm{T}_{\mathrm{BV}}=\left[1-\left[\frac{\varepsilon_{r} \cos \theta-\left(\varepsilon_{r}-\sin ^{2} \theta\right)^{\frac{1}{2}}}{\varepsilon_{r} \cos \theta+\left(\varepsilon_{r}-\sin ^{2} \theta\right)^{\frac{1}{2}}}\right]^{2}\right] \times T_{p h y} \ldots \ldots \ldots \ldots \ldots \ldots \ldots \ldots \ldots \ldots
\end{aligned}
$$

2-When the atmospheric absorption is incorporated, the value of $\mathrm{T}_{\mathrm{BV}}$ gets modified from Eq. (6) and is given as(Stogryn, 1967): 


$$
\begin{aligned}
& \mathrm{T}_{\mathbf{B V}}=\mathrm{L}(\mathrm{z}, \Theta) *\left[\mathrm{E}_{\mathbf{m}}(\mathrm{V}) * \mathrm{~T}_{\mathbf{s}}+\left(1-\mathrm{E}_{\mathbf{m}}(\mathrm{V})\right)^{*} \mathrm{~T}_{\mathbf{s k y}}(\Theta)\right]+\mathrm{T}_{\mathbf{a t m}}(\mathrm{z}, \Theta) \ldots \ldots \ldots \ldots . . .9
\end{aligned}
$$

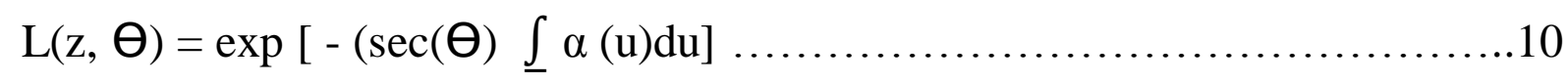

$$
\begin{aligned}
& \mathrm{T}_{\text {sky }}(\Theta)=\sec (\Theta) \int \mathrm{T}_{\text {air }}\left(\mathrm{z}^{\prime}\right) \alpha\left(\mathrm{z}^{\prime}\right) \mathrm{dz} \mathrm{x} \exp \left[-\sec (\Theta) \mathrm{x} \int \alpha(\mathrm{u}) \mathrm{du}\right] \mathrm{dz} \mathrm{z}^{\prime} \ldots \ldots \ldots \ldots . . . .11 \\
& \mathrm{~T}_{\mathrm{atm}}(\mathrm{z}, \Theta)=\sec (\Theta) \int \mathrm{T}_{\mathrm{air}}\left(\mathrm{z}^{\prime}\right) \alpha\left(\mathrm{z}^{\prime}\right) \mathrm{dz} \mathrm{x} \exp \left[-\sec (\Theta) \times \int \alpha(\mathrm{u}) \mathrm{du}\right] \mathrm{dz} \mathrm{z}^{\prime} \ldots \ldots \ldots \ldots 12
\end{aligned}
$$

$\mathrm{A}(\mathrm{u})$ is total absorption coefficient of the atmosphere at an altitude $(\mathrm{u}) . \mathrm{T}_{\text {air }}$ $(Z, \Theta), T_{\text {sky }}(\Theta)$ is the thermometric temperature profile of the air and of the sky. $\mathrm{T}_{\mathrm{atm}}(\mathrm{z}, \Theta)$ is the thermometric temperature profile of the atmosphere.

3- $\mathbf{T}_{\mathbf{B V}}(\theta)$ has a maximum value angle $\theta=\theta \boldsymbol{m}$ which corresponds to the well known Brewster phenomenon. The value of $\theta$ mcan be analytically found out by setting $\mathrm{dT}_{\mathrm{BV}} / \mathrm{d} \theta$ equal to zero which on simplification gives (Hidy et al., 1978):

$\left.\theta_{m}=\operatorname{Cos}^{-1}\left[\frac{\left(\varepsilon_{1}-1\right)+\left[\left(\varepsilon_{1}-1\right)^{2}+\left\{\left(\varepsilon_{1}+\varepsilon_{2}{ }^{2}\right)^{2}-1\right\}\left(\varepsilon_{1}+\varepsilon_{2}{ }^{2}+1\right)\right.}{\left\{\left(\varepsilon_{1}{ }^{2}+\varepsilon_{2}\right)^{2}-1\right\}}\right]^{0.5}\right]^{0.5}$,

\section{EXPERIMENTAL METHOD AND MEASUREMENT TECHNIQUES}

The overall objective of this research was to measure the dielectric properties of water at several frequencies in the 0.7 to $32 \mathrm{GHz}$ range, then to compute the emissivity and brightness temperature from radiative transfer model. The technique used in the present measurement is the microwave bridge as shown in (Fig.1 and 2), two measurement techniques (Sucher and Fox, 1963)were chosen. The first is a waveguide transmission technique, which were uses frequencies between 1 and $6 \mathrm{GHz}$ bands, and the second is a free-space transmission technique, which was used for measurements at four frequencies between 9 and $32 \mathrm{GHz}$.

\section{A-Waveguide transmission Technique.}

The block diagram shown in Fig. 1 is a standard arrangement for measuring the amplitude and phase of the TE10 mode transmission coefficient for a dielectric sample of length L. This is obtained by comparing the amplitude and phase readings of the network-analyzer indicator for the sample holder when it is empty and when it is filled with a sample. Thus the measured quantities are |Tm|, the magnitude of the field transmission coefficient, and $\Phi_{\mathrm{m}}$, the phase of $\mathrm{Tm}$. 
Transmission Coefficient with isolators placed on both sides of the dielectricfilled waveguide (sample holder). The transmission coefficient $\mathrm{Tm}$ may be computed using transmission-line formulations, the result is (Sucher and Fox, 1963; Hallikainen et al., 1985).

$\mathrm{T}_{\mathrm{m}}=\left|\mathrm{T}_{\mathrm{m}}\right| \mathrm{e}^{j \Phi \mathrm{m}}=\frac{\left(1-\mathrm{r}^{2}\right) \mathrm{e}^{-\gamma \mathrm{L}}}{\left(1-\mathrm{r}^{2} \mathrm{e}^{-2 \gamma \mathrm{L}}\right)}$

Where $r$ is the reflection coefficient, $\gamma$ is the propagation constant of the dielectric-filled waveguide is defined in terms of the attenuation coefficient $\alpha$ and the phase factor $\beta$ as(Hallikainen, et al., 1985; Geiger and Williams,1972).

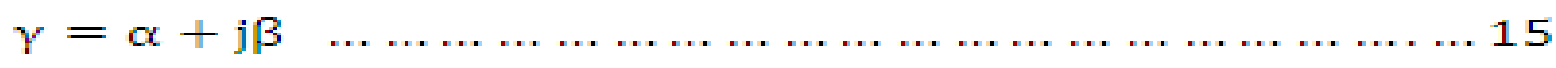

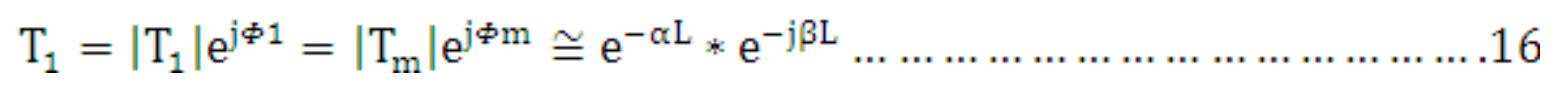

$\alpha=\ln \left(\left|\mathrm{T}_{\mathrm{m}}\right|\right) / \mathrm{L}$

$\mathrm{B}=\Phi / \mathrm{L}$

The propagation constants $\beta_{\mathrm{o}}$ and $\gamma=\alpha+\mathrm{j} \beta$ are given by (Hallikainen, et al., 1985; Geiger and Williams,1972).

$$
\begin{aligned}
& \beta_{\mathrm{o}}=\frac{2 \pi}{\lambda_{\mathrm{go}}} \ldots \ldots \ldots \ldots \ldots . . . . . . . . \\
& \lambda_{\mathrm{go}}=\lambda_{\mathrm{o}}\left[1-\left(\frac{\lambda_{\mathrm{o}}}{\lambda_{\mathrm{c}}}\right)^{2}\right]^{-0.5} \ldots \\
& \beta_{\mathrm{o}}=\frac{2 \pi}{\lambda_{\mathrm{o}}}\left[1-\left(\frac{\lambda_{\mathrm{o}}}{\lambda_{\mathrm{c}}}\right)^{2}\right]^{0.5} \ldots
\end{aligned}
$$




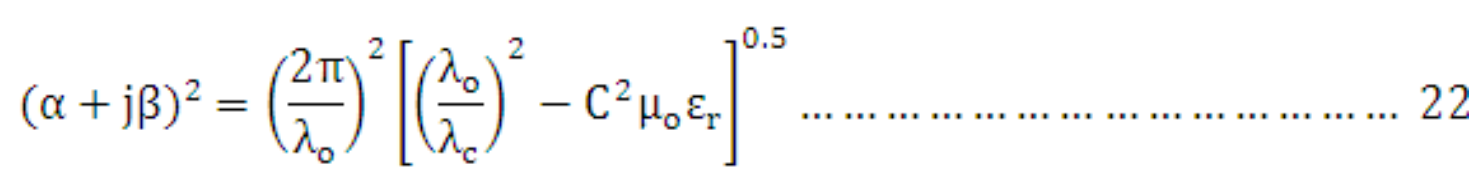

Where $\lambda_{\mathrm{c}}=2 \mathrm{a}$ is the cutoff wavelength of the guide with width a for the TE10 mode, $\mu_{0}$ is the permeability of the free space, and $\varepsilon_{\mathrm{r}}$ is the relative complex dielectric constant of the Sample $\left(\varepsilon_{\mathrm{r}}=\varepsilon^{*} / \varepsilon_{\mathrm{o}}=\varepsilon_{1}-\mathrm{j} \varepsilon_{2}\right)$. $\beta_{\mathrm{o}}$ is the propagation constant in guide for free space, $\lambda_{\mathrm{go}}$ is the air-filled guide wavelength, and $\mathrm{C}$ is the velocity of light. According to (14) and (15) $|\operatorname{Tm}|=\operatorname{Tm}(\alpha, \beta)$ and $\Phi_{\mathrm{m}}=\Phi_{\mathrm{m}}(\alpha, \beta)$. Thus in principle, given measured values for $|\mathrm{Tm}|$ and $\Phi_{\mathrm{m}}$, The quantities $\alpha$ and $\beta$ can be determined from eq.(17) and eq.(18). Once these quantities are determined, $\varepsilon_{1}$ and $\varepsilon_{2}$ can be computed using (Geiger and Williams,1972; Hallikainen, et al., 1983).

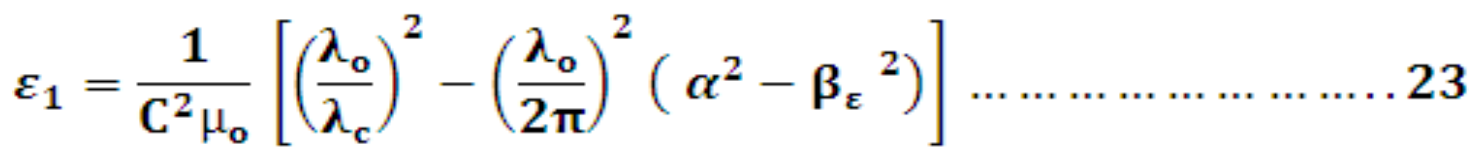

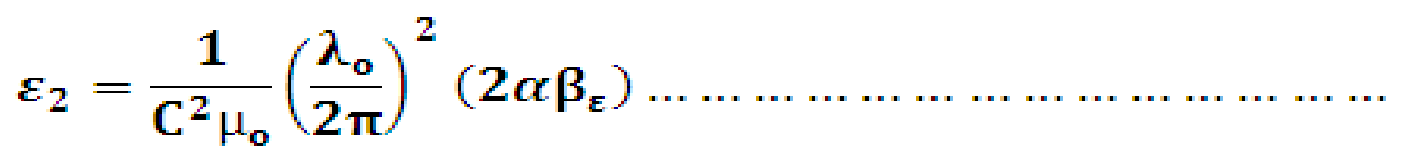

B-Free-Space Transmission Technique.

The free-space transmission system shown in Fig. 2 is basically similar to the waveguide system except that instead of using a dielectric-filled waveguide, the free-space system uses a small horn antennas and a sample holder. The antenna separation is $23 \mathrm{~cm}$ and the sample diameter is $30 \mathrm{~cm}$. Two methods are used to account for multiple reflection. A pulley system is used to vary the sample location between the horn antennas during measurement of the phase shift, and swept frequency loss measurements are used to record the average reflections (Hallikainen et al., 1985). The radiation emitted from the horn is plane wave, where the sample being mounted in a suitable holder and rotated about vertical axis in order to ensure incidence between the two horns. The wave guide reference arm of the bridge contains the rotary vane attenuator. The bridge (with an empty dish in free space arm) is first balanced with varying the reference attenuator and the phase shifter to ensure a minimum detectable signal at the detector. At the balance condition the two signals arriving at the detector from the two arms of the bridge are equal in amplitude. 
The change in attenuator and phase shifter in the reference arm gives a measure of the attenuator and phase shift which produced by the putting of water samples in the dish of the free space arm. These measurements are obtained for many repeated water sample parameters, and by using appropriate equations, the electrical parameters of each are estimated from their measured values. The method of determining $\alpha$ and $\beta \varepsilon$, from the definitions of $\alpha$ and $\beta \varepsilon$ suggest their method of measurement. The TE wave amplitude attenuation in a sample of length $\mathrm{L}$ is given by $\boldsymbol{e}^{-\alpha L}$. If the net power attenuation (attenuation with sample in dish minus attenuation in the empty dish) is A, $\alpha$ can be calculated from (Geiger and Williams, 1972).

$\alpha=\mathrm{A} / 8.6 * \mathrm{~L}$

Similarly, if the length of the sample is changed by $\Delta \mathbf{L}$, and the accompanying phase shift in the transmitted wave is $\Delta \boldsymbol{\Phi}$, (Geiger and Williams, 1972) then solving equation (22) for $\varepsilon_{1}$ and $\varepsilon_{2}$ gives the result (Geiger and Williams,1972) in equation (23) and (24).

$\beta \varepsilon=(\Delta \Phi / \Delta \mathrm{L})+\beta \mathrm{o}=2 \pi / \lambda_{\mathrm{g}}$

$\lambda_{\mathrm{g} \varepsilon}=\lambda_{\mathrm{o}}\left[\frac{\varepsilon^{*}}{\varepsilon_{\mathrm{o}}}-\left(\frac{\lambda_{\mathrm{o}}}{\lambda_{\mathrm{c}}}\right)^{2}\right]^{-0.5}$

$\beta_{\varepsilon}=\frac{2 \pi}{\lambda_{\mathrm{o}}}\left[\frac{\varepsilon^{*}}{\varepsilon_{\mathrm{o}}}-\left(\frac{\lambda_{\mathrm{o}}}{\lambda_{\mathrm{c}}}\right)^{2}\right]^{0.5}$ 


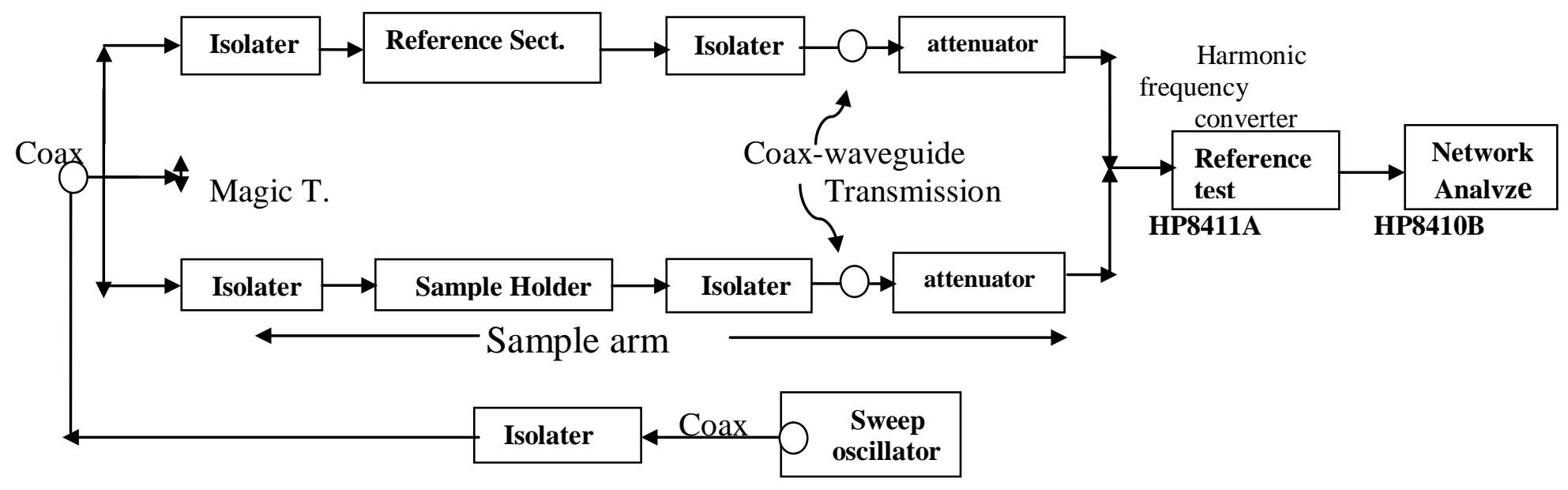

Fig. 1 : Block Diagram of the 1-6GHz Waveguide Transmission Measurement System.

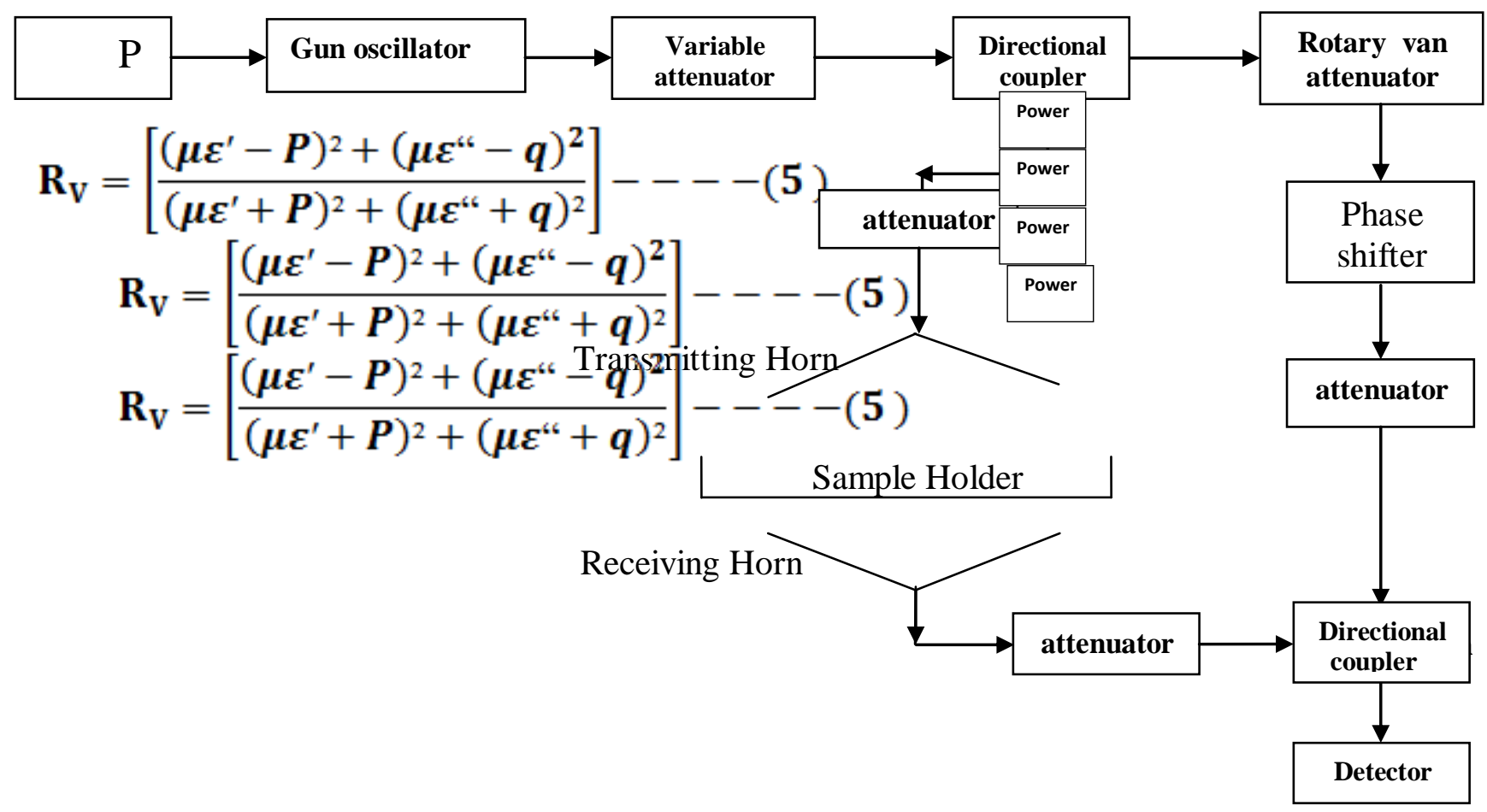

Fig. 2 : Block Diagram of the 9-32GHz Free-Space Measurement System. 


\section{RESULTS AND DISCUSSION}

The relative complex dielectric constant of water samples may be written as ( $\varepsilon_{\mathrm{r}}=\varepsilon_{1}-\varepsilon_{2}$ ), $\varepsilon_{1}$ and $\varepsilon_{2}$ and calculated from measured values of the attenuation coefficient and phase shift $(\alpha, \beta)$ by using the method described previously. These measurements are repeated for twenty samples taken from different Mediterranean Sea sites far from shore beside Lipda (less than $3 \mathrm{Km}$ ) and samples from freshwater (pure water). The statistical results are listed in (Table 1). The final result for real dielectric constant $\left(\boldsymbol{\varepsilon}_{1}\right)$ and imaginary dielectric constant $\left(\boldsymbol{\varepsilon}_{2}\right)$ as a function of frequency at surface temperature $T_{\text {phy }}=297^{\circ} \mathrm{K}$, salinity $S=33 \mathrm{psu}$, conductivity 5 mmhos $/ \mathrm{m}$, and For freshwater $\mathrm{T}_{\text {phy }}=297^{\circ} \mathrm{K}, \mathrm{S}=0$ and conductivity $0.001 \mathrm{mmhos} / \mathrm{m}$ are represented in ( Fig. 3). It has been observed from the figure that the $\left(\boldsymbol{\varepsilon}_{1}\right)$ is inversely proportional with the frequency, whereas $\left(\varepsilon_{2}\right)$ is directly proportional with frequency, and the values of dielectric constant for sea are slightly larger than those for freshwater due to presence of salinity in sea water.

Table 1:The Experimental Values of Complex Dielectric Constant of Seawater and Freshwater at $293^{\circ} \mathrm{K}$.

\begin{tabular}{|c|c|c|c|c|}
\hline Frequency & \multicolumn{2}{|c|}{ Dielectric constant of fresh water } & \multicolumn{2}{c|}{ Dielectric constant of sea water } \\
\hline $\mathrm{f} \mathrm{GHz}$ & $\varepsilon_{1}$ & $\varepsilon_{2}$ & $\varepsilon_{1}$ & $\varepsilon_{2}$ \\
\hline 0.7 & 80.2 & 2.4 & 81.36 & 2.8 \\
\hline 1.45 & 78.8 & 5.5 & 79.5 & 6.5 \\
\hline 1.75 & 72.5 & 6.4 & 79.2 & 7.9 \\
\hline 3.0 & 76.2 & 11.59 & 77.2 & 13.1 \\
\hline 3.7 & 74.9 & 15.5 & 76.2 & 15.6 \\
\hline 5.0 & 71.3 & 17.5 & 73.4 & 20.7 \\
\hline 9.3 & 61.5 & 28.3 & 64.7 & 30.4 \\
\hline 22.2 & 30.37 & 35.3 & 37.0 & 35.2 \\
\hline 31.4 & 23.4 & 32.2 & 24 & 29.1 \\
\hline
\end{tabular}




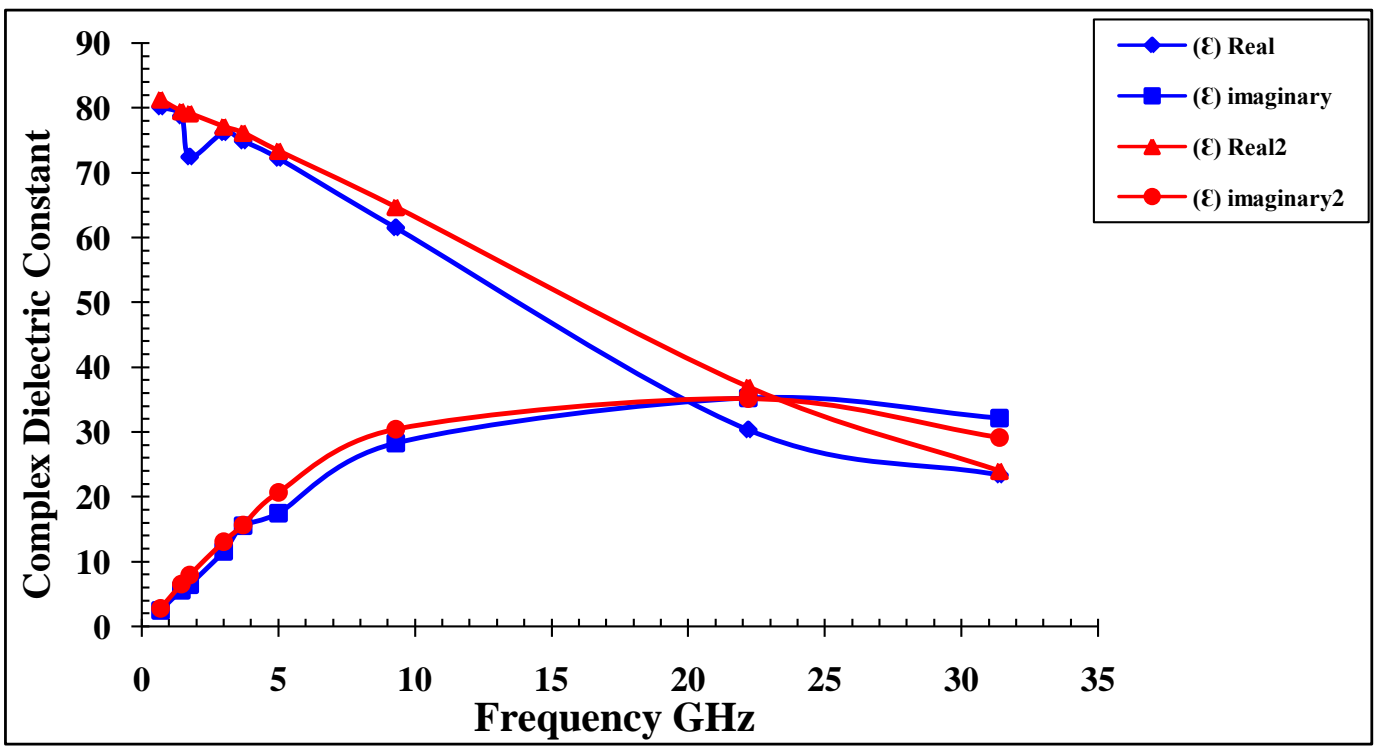

Fig. 3: The Experimental Values of Complex Dielectric Constant of Sea Water and Fresh Water at $293^{\circ} \mathrm{K}$ and at Different Frequencies.

Additional measurements were made at frequency of $1.75 \mathrm{GHz}$ on fresh water over the temperature range of $273^{\circ} \mathrm{K}$ to $323^{\circ} \mathrm{K}$. The calculated values of $\left(\boldsymbol{\varepsilon}_{\mathbf{1}}\right)$ and $\left(\boldsymbol{\varepsilon}_{2}\right)$ are given in (Table 2) and represented in (Fig. 4). It has been observed from the figure that the dielectric constant of water depends on temperature.

Table 2: The Complex Dielectric Constant of Fresh Water at Different Temperatures.

\begin{tabular}{|c|c|c|}
\hline Temperature & \multicolumn{2}{|c|}{$\mathrm{f}=1.75 \mathrm{GHz}$} \\
\hline $\mathrm{T}_{\mathrm{B}}{ }^{0} \mathrm{~K}$ & $\left(\varepsilon_{1}\right)_{\text {Real }}$ & $\left(\varepsilon_{2}\right)_{\text {Imaginary }}$ \\
\hline 273 & 85.3 & 16.5 \\
\hline 283 & 82.4 & 11.0 \\
\hline 293 & 79.2 & 7.9 \\
\hline 303 & 76.1 & 5.8 \\
\hline 313 & 72.9 & 4.4 \\
\hline 323 & 60.7 & 3.6 \\
\hline
\end{tabular}




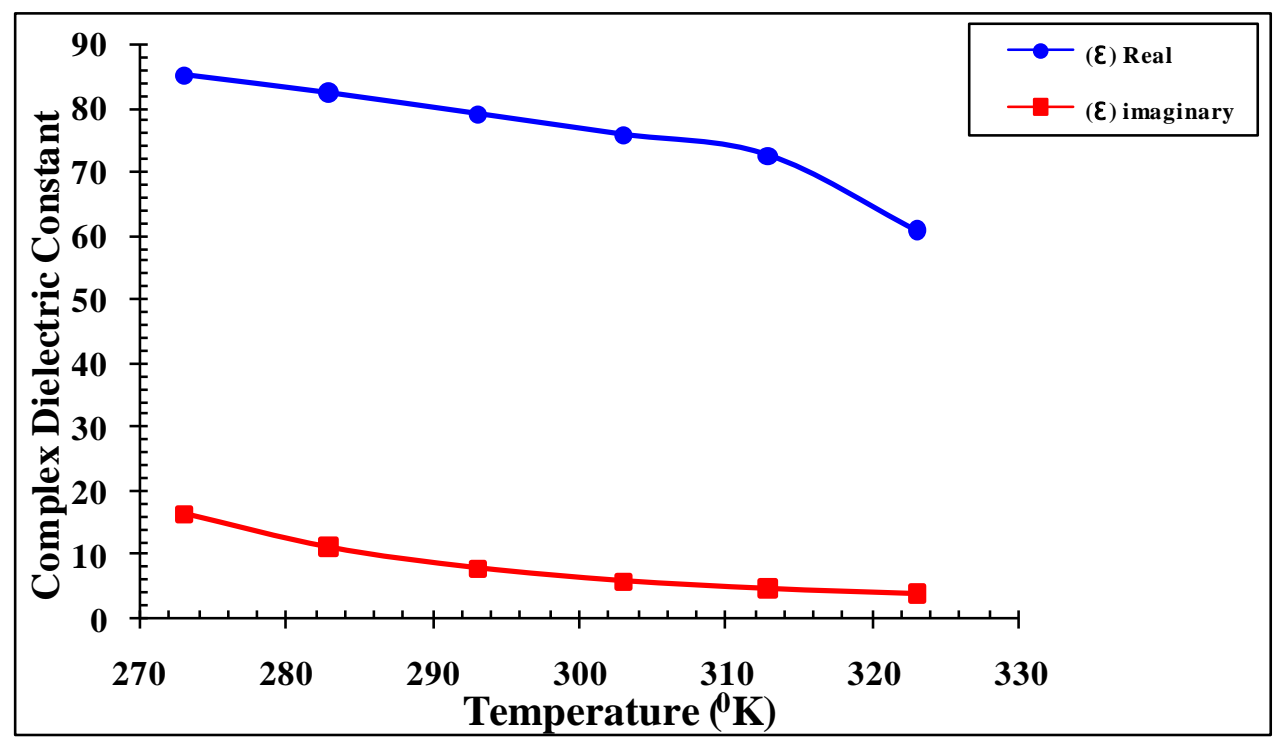

Fig. 4: The Complex Dielectric Constant of Fresh Water at Different Temperatures.

The computed results for brightness temperature at horizontal and vertical polarization as a function of frequencies are listed in (Table 3). Figure (5) shows the brightness temperature of the sea surface at incidence angle zero and 45 degree, from this figure it may be noticed that the brightness temperature increases as the frequency increases. This means that the brightness temperature depends on frequency. At those frequencies the brightness temperature (for horizontal polarization) at incidence angle $45^{\circ}$ is less than the brightness temperature at incidence angle $0^{\circ}$, whereas the brightness temperature(for vertical polarization) at incidence angle $45^{\circ}$ is more than the brightness temperature at incidence angle $0^{\circ}$; this mean that as the incidence angle increases the brightness temperature(at vertical polarization) increases and the brightness temperature depends on the incidence angle and on the polarization.

Table 3: Variation of Brightness Temperature as a Function of Frequency at Incidence Angle 0, and 45 Degree.

\begin{tabular}{|c|c|c|c|c|}
\hline \multirow{2}{*}{$\begin{array}{c}\text { Frequenc } \\
\mathbf{y} \\
\mathrm{GHz}\end{array}$} & \multicolumn{2}{|c|}{ Incidence angle=0 degree } & \multicolumn{2}{l|}{$\begin{array}{l}\text { Incidence angle }=45 \\
\text { degree }\end{array}$} \\
\cline { 2 - 5 } & $\mathrm{T}_{\mathrm{BH}}$ & $\mathrm{T}_{\mathrm{BV}}$ & $\mathrm{T}_{\mathrm{BH}}$ & $\mathrm{T}_{\mathrm{BV}}$ \\
\hline 0.7 & 74.1990 & 110.44 & 45.4981 & 142.1467 \\
\hline 1.45 & 84.3556 & 110.6933 & 56.93976 & 142.4373 \\
\hline 3.0 & 101.1755 & 111.2428 & 75.8566 & 143.0796 \\
\hline 9.3 & 146.0152 & 114.2 & 125.962 & 146.8309 \\
\hline 22.23 & 182.364 & 125.776 & 165.1857 & 159.7946 \\
\hline 31.4 & 188.2058 & 135.6564 & 169.8187 & 170.9367 \\
\hline
\end{tabular}




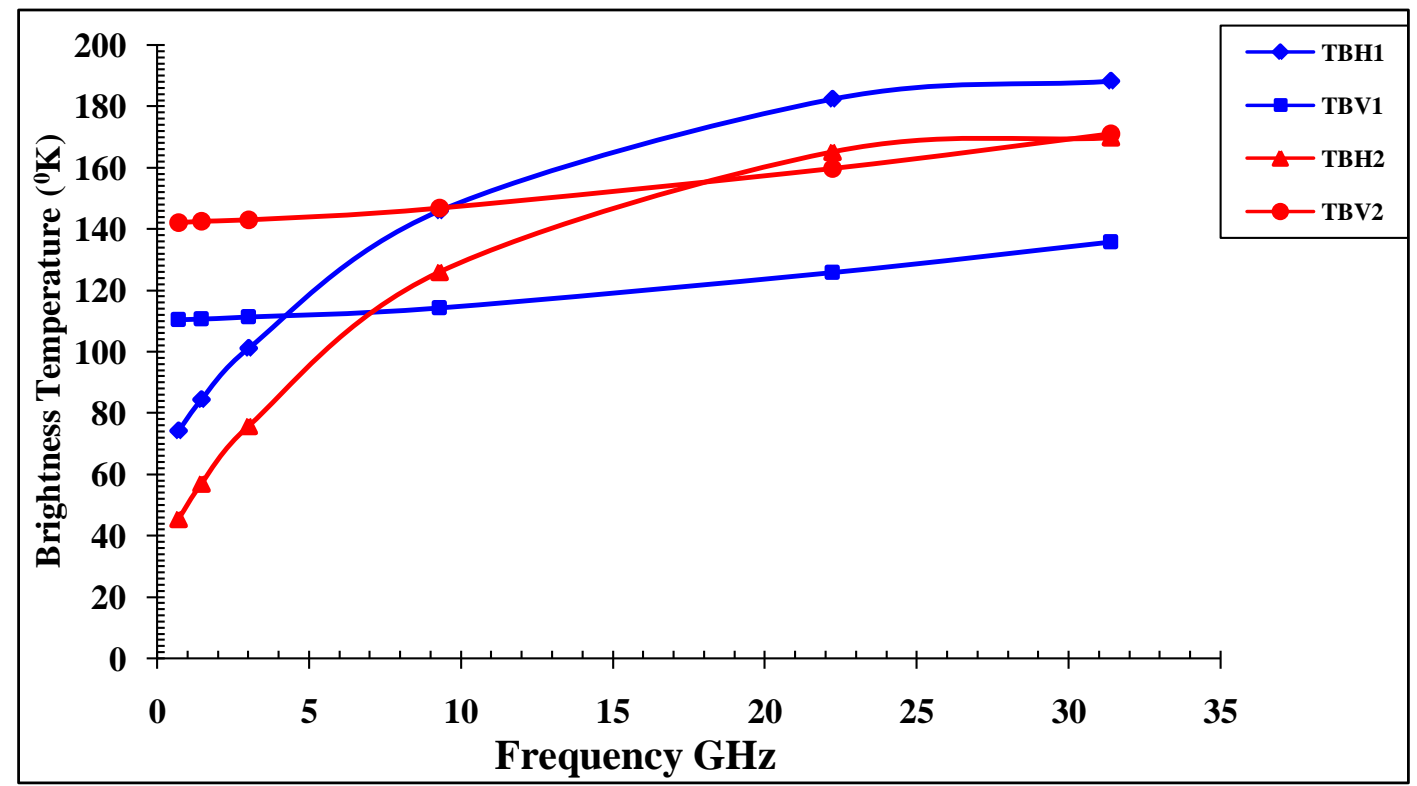

Fig. 5: Variation of Brightness Temperature as a Function of Frequency at Incidence Angle 0, and 45 Degree.

By using the radiative transfer model (RTM), numerical computation has been carried out for both cases, i.e. when the atmospheric and surface scattering effects are not taken into account Eq.(8) and when the atmospheric absorption are incorporated Eq.(9), due to columnar water vapor and columnar liquid cloud water over sea surface with temperature $\mathrm{T}_{\text {phy }}=297^{\circ} \mathrm{K}$ at different frequencies. The temperature of the water surface plays a key role in determining the radiation emitted by the surface. The wind speed is considered as below $5 \mathrm{~m} / \mathrm{sec}$ (from meteoroligical station, lipda), the sea surface can be regarded as specular and calm water. The computed results for brightness temperature for both cases (i.e. with and without atmosphere effect) are listed in table (4). Figure (6) shows the brightness temperature of the sea surface at frequency 3.0,9.3,19.3,22.23, and 31.4 $\mathrm{GHz}$ as a function of incidence angle. It has also been observed from figure (6) that the brightness temperature, when the atmospheric and surface scattering effects due to columnar water vapor and columnar liquid cloud water are not taken into account, is lower than that with atmospheric absorption.

Table (5) shows numerical computation of brightness temperature for both cases at Brewster angle. It has been observed from (Table 5) that the value of the incidence angle at which the Brewster angle occurs decreases when the frequency increases. 
Table 4: Variation of Brightness Temperature as a Function of Incidence angle (with Without Atmospheric Effect) at Frequencies3, 9.3,19.3, and 31.4 GHz.

\begin{tabular}{|c|c|c|c|c|c|c|c|c|}
\hline \multirow[b]{2}{*}{$\underset{\boldsymbol{\theta}^{\mathbf{0}}}{\text { Angle }}$} & \multicolumn{2}{|c|}{$T_{B V}$ at $f=3.0 \mathrm{GHz}$} & \multicolumn{2}{|c|}{$T_{B V}$ at $f=9.3 \mathrm{GHz}$} & \multicolumn{2}{|c|}{$T_{B V}$ at $f=19.3 \mathrm{GHz}$} & \multicolumn{2}{|c|}{$\mathrm{T}_{\mathrm{BV}}$ at $\mathrm{f}=31.4 \mathrm{GHz}$} \\
\hline & $\begin{array}{l}\text { Without } \\
\text { atm. } \\
\text { effect }\end{array}$ & $\begin{array}{l}\text { With } \\
\text { atm. } \\
\text { effect }\end{array}$ & $\begin{array}{c}\text { Without } \\
\text { atm. } \\
\text { effect }\end{array}$ & 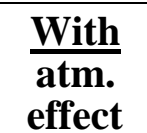 & $\begin{array}{l}\text { Without } \\
\text { atm. } \\
\text { effect }\end{array}$ & $\begin{array}{l}\frac{\text { With }}{\text { atm. }} \\
\text { Effect }\end{array}$ & $\begin{array}{l}\text { Without } \\
\text { atm. } \\
\text { Effect }\end{array}$ & $\begin{array}{l}\frac{\text { With }}{\text { atm. }} \\
\text { Effect }\end{array}$ \\
\hline 0 & 111.243 & 168.253 & 114.461 & 175.247 & 116 & 160.0 & 125.0 & 165.0 \\
\hline 15 & 114.173 & 178.182 & 117.451 & 186.524 & 122 & 228.0 & 132.0299 & 180.0 \\
\hline 30 & 123.78 & 184.8526 & 127.241 & 190.624 & 135 & 236 & 142.5132 & 188 \\
\hline 45 & 143.0796 & 198.1624 & 146.831 & 199.624 & 154.4 & 245 & 160.0 & 198.0 \\
\hline 60 & 179.67 & 211.034 & 183.65 & 215.853 & 205 & 265 & 192.0 & 232 \\
\hline 75 & 251.017 & 262.288 & 253.624 & 261.63 & 280. & 276 & 240.0 & 268 \\
\hline 90 & 5.48 & 5.45 & 5.440 & 5.862 & 5.56 & 5.5 & 5.246 & 5.84 \\
\hline
\end{tabular}

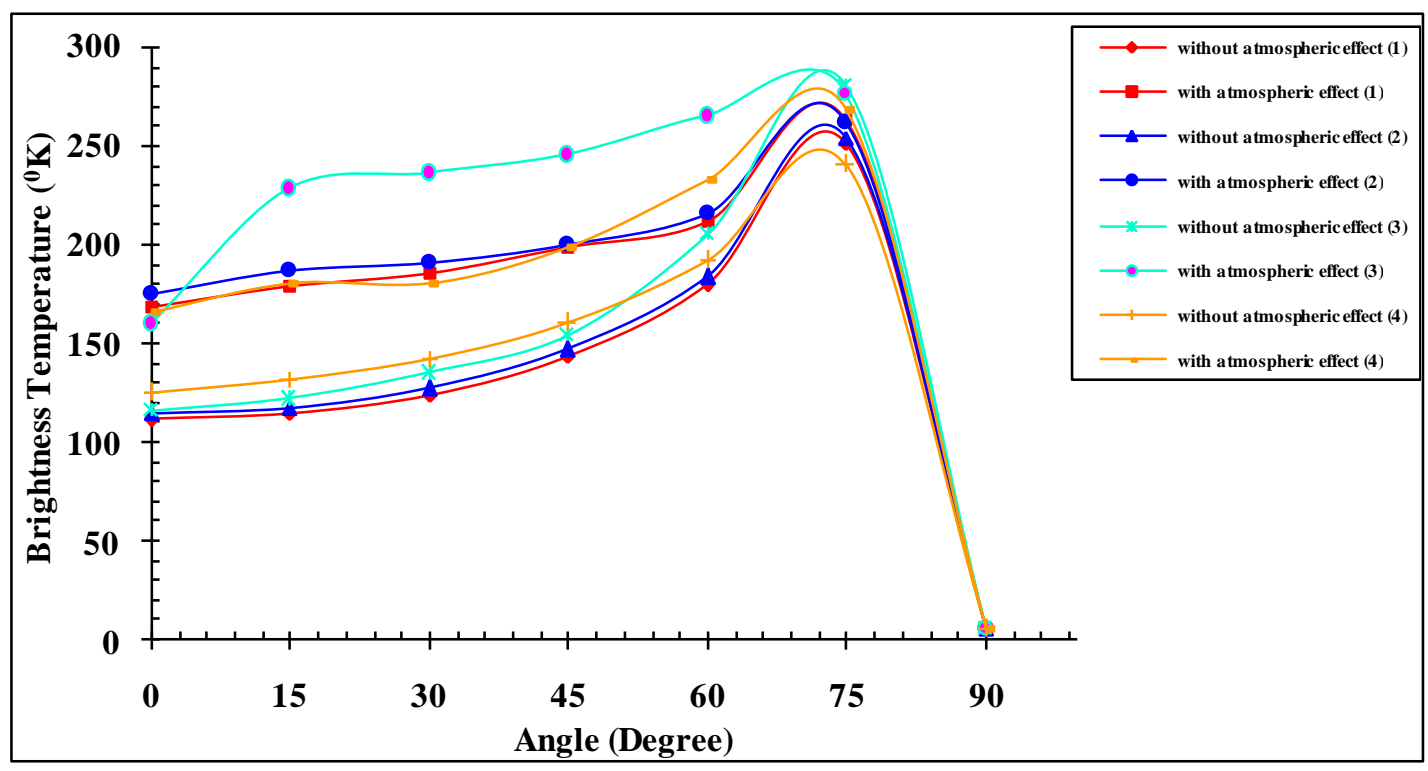

Fig. 6: Variation of Brightness Temperature as a Function of Incidence Angle (with and Without Atmospheric Effect) at Frequencies 3, 9.3,19.3, and 31.4 GHz.

Table 5: Variation of Brightness Temperature at a Brewster Angle (with and without Atmospheric Effect) at Frequencies 3, 9.3,19.3, 22.23, and 31.4 GHz.

\begin{tabular}{|c|c|c|c|}
\hline \multirow{2}{*}{$\mathbf{f ~ G H z}$} & $\boldsymbol{\theta}_{\mathbf{m}}$ & $\mathbf{T}_{\mathbf{B V}}$ & $\mathbf{T}_{\mathbf{B V}}$ \\
\cline { 2 - 4 } & Brewster angle & Without atm. effect & With atm. Effect \\
\hline 3.0 & $82.63^{\circ}$ & $251^{\circ} \mathrm{K}$ & $248^{\circ} \mathrm{K}$ \\
\hline 9.3 & $82.2^{\circ}$ & $253^{\circ} \mathrm{K}$ & $255^{\circ} \mathrm{K}$ \\
\hline 19.3 & $82.19^{\circ}$ & $251^{\circ} \mathrm{K}$ & $255^{\circ} \mathrm{K}$ \\
\hline 22.23 & $81.93^{\circ}$ & $262^{\circ} \mathrm{K}$ & $272^{\circ} \mathrm{K}$ \\
\hline 31.4 & $81.08^{\circ}$ & $240^{\circ} \mathrm{K}$ & $268^{\circ} \mathrm{K}$ \\
\hline
\end{tabular}


Sea surface thermal microwave emission as characterized by its radiometric brightness temperature $\mathbf{T}_{\mathbf{B}}$ has been calculated using Eq.(8) (Wilbeit, 1978) and emissivity $\mathrm{E}_{\mathrm{m}}$ from Eq.(2). The polarization parameters of sea surface emission are determined at various view angles and different weather conditions.

Figure (7) shows the emissivity of the sea surface at frequencies $(3,9.3,22.23,31.4 \mathrm{GHz})$. From the figure, the emissivity for $\mathrm{V}$ - polarization has been observed to increase as the surface temperature increases and as frequency increases, whereas for $\mathrm{H}$ - polarization the emissivity decreases as the incidences, angle increase. Table (6) lists the calculated data from (RTM) for emissivity as a function of surface temperature at different frequencies. Figure 8 , shows the brightness temperature for the sea surface at frequencies $(3,9.3,22.23,31.4 \mathrm{GHz})$ as a function of incidence angle for both polarization. From (Fig. 8), the brightness temperature for $\mathrm{V}$-polarization is noticed to increase as the surface temperature increases. This means the brightness temperature of sea surface is dependent on sea surface temperature, frequency and salinity. It has also been observed that the value of the incidence angle, at which the Brewster angle occurs, decreases when the frequency increase. Table (7) lists the calculated data from (RTM) for the brightness temperature as a function of surface temperature at different frequencies.

Table 6: Variation of Emissivity as a Function of Incidence Angle (at Horizontal and Vertical Polarization) at Frequencies 3.0, 9.3, 22.23, and 31.4 GHz.

\begin{tabular}{|c|c|c|c|c|c|c|c|c|}
\hline \multirow{2}{*}{$\begin{array}{c}\text { Angle } \\
\boldsymbol{\theta}^{\mathbf{0}}\end{array}$} & \multicolumn{2}{|c|}{$\mathbf{f}=\mathbf{3 . 0} \mathbf{G H z}$} & \multicolumn{2}{|c|}{$\mathbf{f}=\mathbf{9 . 3} \mathbf{G H z}$} & \multicolumn{2}{|c|}{$\mathbf{f = 2 2 . 2 3} \mathbf{G H z}$} & \multicolumn{2}{|c|}{$\mathbf{f = 3 1 . 4} \mathbf{G H z}$} \\
\cline { 2 - 8 } & $\mathbf{E}_{\mathbf{H}}$ & $\mathbf{E}_{\mathbf{V}}$ & $\mathbf{E}_{\mathbf{H}}$ & $\mathbf{E}_{\mathbf{V}}$ & $\mathbf{E}_{\mathbf{H}}$ & $\mathbf{E}_{\mathbf{V}}$ & $\mathbf{E}_{\mathbf{H}}$ & $\mathbf{E}_{\mathbf{V}}$ \\
\hline $\mathbf{0}$ & 0.329368 & 0.363845 & 0.48293 & 0.37486 & 0.607411 & 0.413617 & 0.625276 & 0.445926 \\
\hline $\mathbf{1 5}$ & 0.318085 & 0.37388 & 0.47401 & 0.38511 & 0.59983 & 0.42453 & 0.617228 & 0.457325 \\
\hline $\mathbf{3 0}$ & 0.286733 & 0.406781 & 0.449191 & 0.418633 & 0.578641 & 0.460060 & 0.594674 & 0.494260 \\
\hline $\mathbf{4 5}$ & 0.24266 & 0.472875 & 0.414253 & 0.48572 & 0.548581 & 0.530119 & 0.552521 & 0.566337 \\
\hline $\mathbf{6 0}$ & 0.197132 & 0.598185 & 0.37811 & 0.61181 & 0.51723 & 0.657531 & 0.528813 & 0.694350 \\
\hline $\mathbf{7 5}$ & 0.162873 & 0.842525 & 0.33488 & 0.851235 & 0.49346 & 0.876362 & 0.503148 & 0.987984 \\
\hline $\mathbf{9 0}$ & 0.150136 & $1.64 * 10^{-3}$ & 0.324075 & $1.51 * 10^{-3}$ & 0.4569 & $1.24 * 10^{-3}$ & 0.493542 & $1.048 * 10^{-3}$ \\
\hline
\end{tabular}




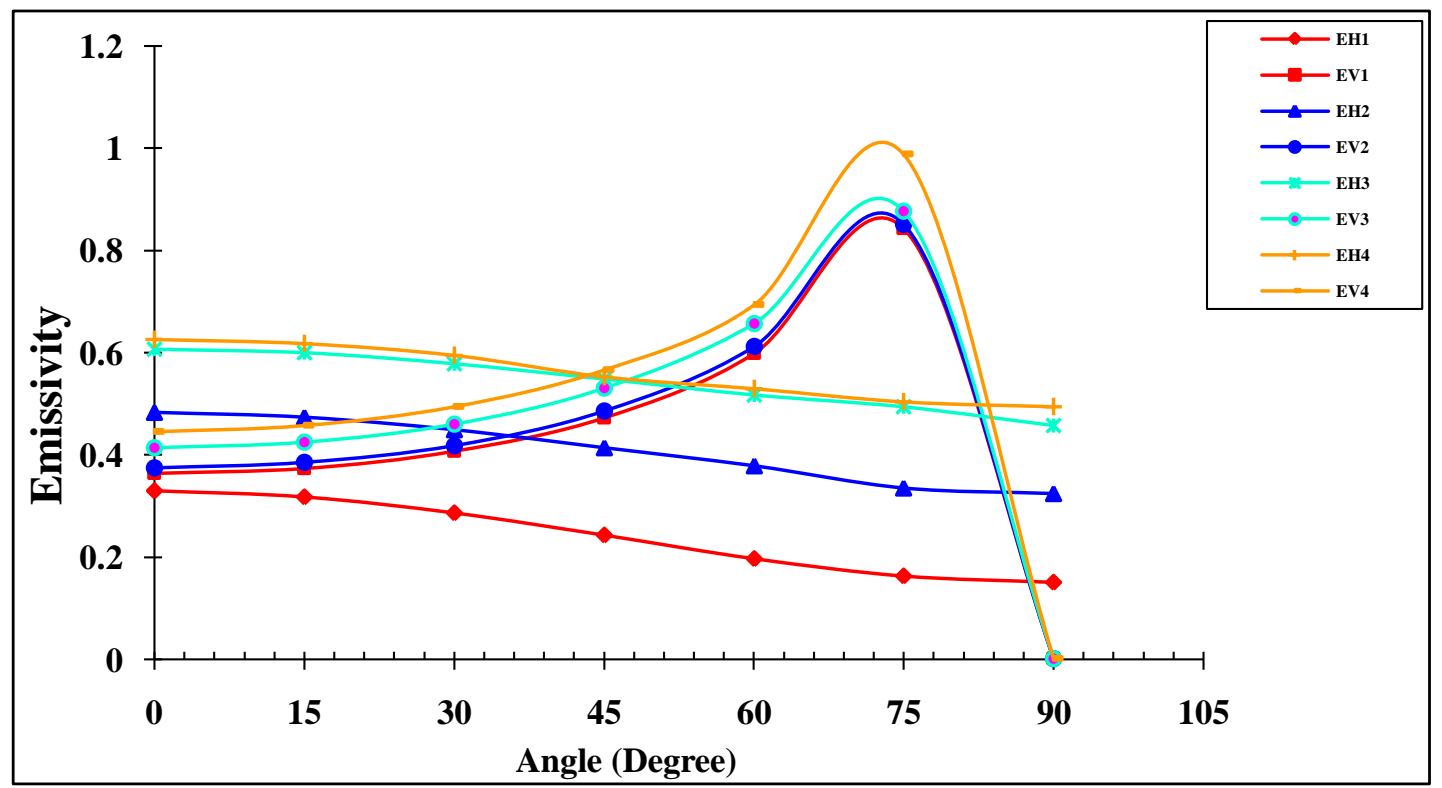

Fig. 7: Variation of Emissivity as a Function of Incidence Angle (at Horizontal and Vertical Polarization) at Frequencies 3.0, 9.3, 22.23, and 31.4 GHz.

Table 7: Variation of Brightness Temperature as a Function of Incidence Angle (at Horizontal and Vertical Polarization) at Frequencies 3.0, 9.3, 22.23, and $31.4 \mathrm{GHz}$.

\begin{tabular}{|c|c|c|c|c|c|c|c|c|}
\hline \multirow{2}{*}{$\underset{\boldsymbol{\theta}^{\mathbf{0}}}{\text { Angle }}$} & \multicolumn{2}{|c|}{$\mathbf{f}=3.0 \mathrm{GHz}$} & \multicolumn{2}{|c|}{$f=9.3 \mathrm{GHz}$} & \multicolumn{2}{|c|}{$\mathrm{f}=22.23 \mathrm{GHz}$} & \multicolumn{2}{|c|}{$\mathrm{f}=31.4 \mathrm{GHz}$} \\
\hline & $\mathbf{T}_{\mathbf{B H}}$ & $\mathbf{T}_{\mathbf{B V}}$ & $\mathbf{T}_{\mathrm{BH}}$ & $\mathbf{T}_{\mathbf{B V}}$ & $\mathbf{T}_{\mathrm{BH}}$ & $\mathbf{T}_{\mathrm{BV}}$ & $\mathbf{T}_{\mathrm{BH}}$ & $\mathbf{T}_{\mathrm{BV}}$ \\
\hline 0 & 101.1755 & 111.2428 & 146.0152 & 114.2 & 182.364 & 125.776 & 188.2058 & 135.6564 \\
\hline 15 & 97.8808 & 114.1729 & 143.4097 & 117.4511 & 180.1498 & 128.964 & 185.8477 & 138.9963 \\
\hline 30 & 88.7261 & 123.7799 & 136.1637 & 127.2408 & 173.963 & 139.3376 & 179.2393 & 149.8183 \\
\hline 45 & 75.8566 & 143.0796 & 125.962 & 146.8309 & 165.1857 & 159.7946 & 169.8187 & 170.9367 \\
\hline 60 & 62.5624 & 179.6699 & 115.408 & 183.6474 & 156.0309 & 196.999 & 159.9423 & 208.4447 \\
\hline 75 & 52.5590 & 251.0172 & 107.4569 & 253.5607 & 149.0889 & 260.8978 & 152.4223 & 268.3479 \\
\hline 90 & 48.8397 & 5.47977 & 104.4986 & 5.44011 & 138.9 & 5.3636 & 149.6078 & 5.305553 \\
\hline
\end{tabular}




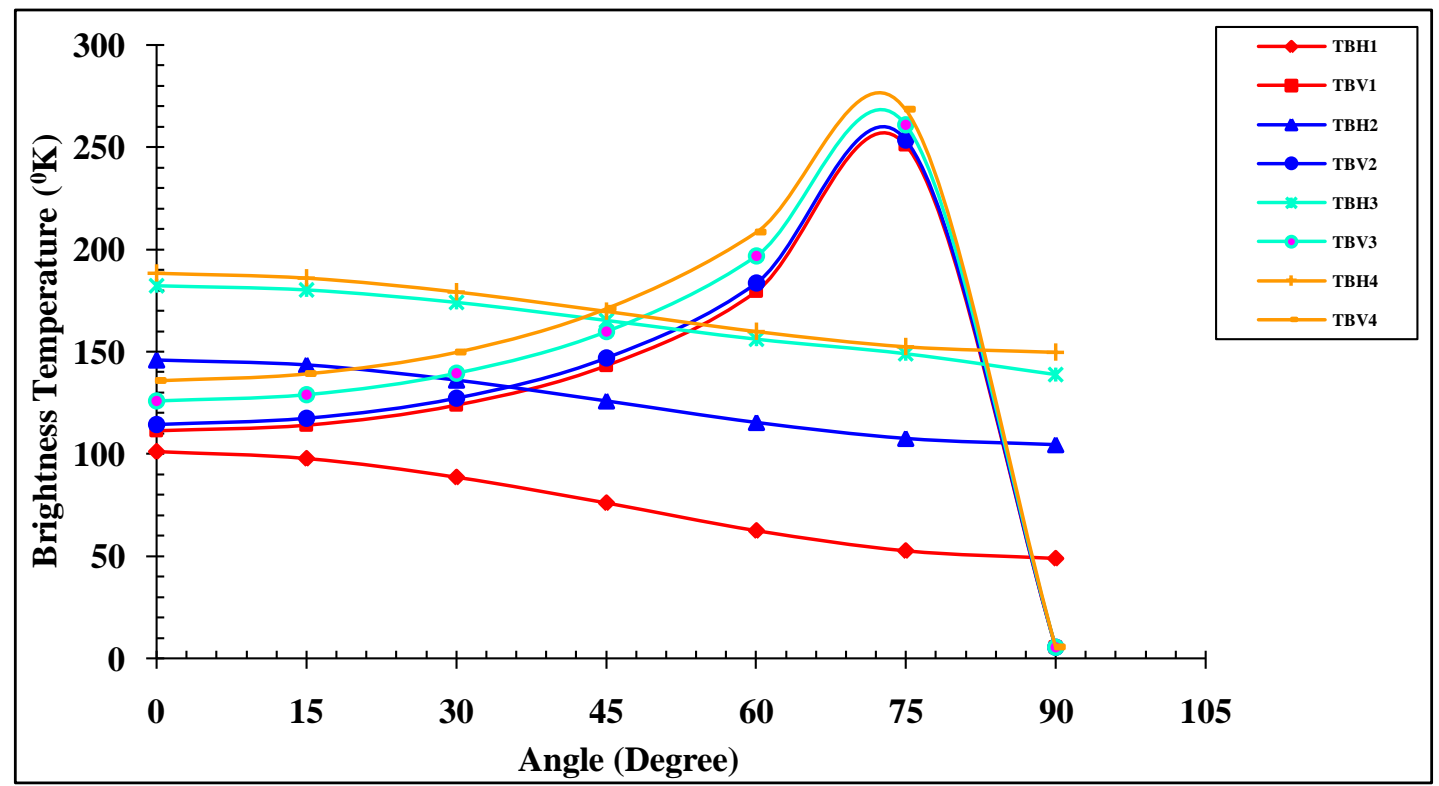

Fig. 8: Variation of Brightness Temperature as a Function of Incidence Angle (at Horizontal and Vertical Polarization) at Frequencies 3.0, 9.3, 22.23, and $\mathrm{GHz}$.

\section{CONCLUSION}

I- The results confirm the correctness of the analytical $\theta \mathrm{m}$ equation (13). The inclusion of atmosphere resulted in some significant change for $22 \mathrm{GHz}$ frequency band. The position of the $\mathrm{T}_{\mathrm{BV}}$ max has shifted and its value is lowered. The lowering is explained by the fact that the effective temperature of atmosphere happens to the lower than the background temperature in that angular range and hence the absorption dominates the measured emission. The variation of brightness temperature is insignificant with $10^{\circ}$ a round nadir and varies approximately linearly up to $45^{\circ}$.

II- Sea surface temperature is an important oceanic and sea variable with significance for a large number of sea and atmosphere applications and for many environmental models including:

1- Numerical weather prediction.

2- global ocean circulation.

3- Energy and water exchange between atmosphere and sea surface.

4-Climate dynamic and environmental prediction.

5- Fisheries management. 


\section{Nomenclature:}

SST = Sea surface temperature .

SSS = Sea surface salinity.

SSR = Sea surface roughness.

EIA $=$ Earth incidence angle.

RTM $=$ Radiative transfer model.

EDRS $=$ Environmental data records.

$\mathrm{SSM} / \mathrm{I}=$ Special sensor microwave $/$ Imager.

$\left(\varepsilon_{1}\right)_{\text {Real }}=$ Dielectric constant (real value).

$\left(\varepsilon_{2}\right)_{\text {Im. }}=$ Dielectric constant (image value).

$\mathrm{P}=$ Polarization.

$\mathrm{H}=$ Horizontal polarization.

$\mathrm{V}=$ Vertical polarization.

$\mathrm{R}=$ Reflectivity.

$\mathrm{E}_{\mathrm{m}}=$ Emissivity.

$\mathrm{T}_{\mathrm{B}}=$ Brightness temperature.

$\mathrm{T}_{\text {phy }}=$ Surface temperature (Physical temperature).

$\mathrm{T}_{\text {sky }}=$ Sky temperature.

$\mathrm{S}=$ Salinity.

PSU $=$ Particle salinity unit.

\section{REFERENCES}

Geiger, F. E., and Williams, D., 1972. Dielectric Constant of Soil at Microwave Frequencies, Goddard Space Flight Center, Greenbelt, Maryland.

Hallikainen, M., and Ulaby, F. T., and Dobson, M.C., 1985. Microwave Dielectric Behavior of Wet Soil-Part I, IEEE Trans. Geophysics and Remote Sensing,Vol.GE-23, No. 1, pp. 25 - 34.

Hidy, G. M., Hall, W. F., and Hardy, W. N., 1972. Development of a Satellite Microwave Radiometer to Sense the Surface Temperature of the World Oceans, NASA CRA, North American Rockwell Corporation, Downey, California.

Klein, L. A. and Swift, C. T., 1977. An Improved For The Dielectric Constant of Sea Water at Microwave Frequencies. IEEE Trans. Antennas Propagate, Vol. AP-25, pp. $104-111$. 
Knight, R.J. and Llewellyn Jones, D.T., 1984. Measurement of The Complex Refractive Index of Sea Ice and Snow Using Microwave United Cavity. Science and Research Council: Rutherford Appleton Laboratory, Ral - 84 - 093, pp. 1 - 12.

Lipton, A. M.; Griffin, A.M. and Ling, A., 1999. Microwave Transfer Made Differences in Remote Sensing of Cloud Liquid Water at Low Temperature. IEEE Trans. Geosci. and Remote Sensing, Vol. 37, No. 1, pp. 620 - 623.

Meissner, T. and Wentz, F.J. 2004. The Complex Dielectric Constant of Pure and Sea Water from Microwave Satellite Observations. IEEE Trans. Geophysics and Remote Sensing, Vol. 42, No. 9, pp. 1836 - 1849.

Meissner, T. and Wentz, F. J., 2003. Radiative Transfer Model Function From SSM/I Brightness Temperature. Remote Sensing System: Sata, Rosa, CA., pp.362-268.

Rosen Kranz, P. W., 2003. Rapid Radiative Transfer Model for AMSU/HSB Channels. IEEE Trans. Geophysics and Remote Sensing, Vol. 41, No. 2, pp. 362 - 268.

Stogryn, A., 1967. The Apparent Temperature of the Sea at Microwave Frequency.

IEEE Trans. Antennas Propagate Microwave, Vol. AP -15, pp. 278 - 286.

Sucher, M. and Fox, J., 1963. Hand Book of Microwave Measurements. New York Poly Technique Press. $3^{\text {rd }}$ Ed., Vol. 2, Chap. 9, pp. 495 - 548.

Swift, C.T., 1980. Passive Microwave Remote Sensing of The Ocean: a review. Boundary Layer Meteorol., Vol. 18, pp. 25 - 54.

Thomas, M. and Frank, J. W., 2004. The Complex Dielectric Constant of Pure and Sea Water from Microwave Satellite Observations. IEEE Transactions on Geoscience and Remote Sensing, Vol. 42, No. 9, pp.1836 - 1849.

Ulaby, F.T.; Moore, R. K. and Fung, A. K., 1986. Microwave Remote Sensing: Active and Passive from Theory to Application, Vol. 3, USA: Artech House, $2162 \mathrm{p}$.

Wentz, F. J., 1983. A Model Function for Ocean Microwave Brightness Temperature. J. Geophysics Res., Vol. 88, No. C3, pp. 1892 - 1908.

Wilheit, T., 1978. Radiative Transfer in a Plane Stratified Dielectric. IEEE Trans. Geo Electron., GE-16, pp. 138 - 143.

\section{Relevant Websites}

http://www.awi-bremernaven.de/index.html, accessed at 21-07-2010 http://www.nodc.noaa.gov/General/salinity.html, accessed at 21-07-2010 http://www.nodc.noaa.gov/OC5/inv_all.html, accessed at 21-07-2010 http://www.nodc.noaa.gov/cgi-bin/JOPI/jopi, accessed at 16-01-2012 http://www.meds-sdmm.dfo-mpo.gc.ca/, accessed at 16-01-2012 http://www.nodc.noaa.gov/GTSPP/gtspp-home.htm, accessed at 16-01-20112, http://lshp.gsfc.nasa.gov/Post2002/smm3.html, accessed at 16-01-2013 C: User $\backslash$ a a $\backslash$ Desktop $\backslash$ SSt $\backslash$ Sea - Surface -Temperature htm, accessed at 8-012012. 